\title{
La Desigualdad Y La Diferencia: Notas Para Pensar Los Trayectos Escolares De Las Personas Trans
}

\section{Desigualdade E Diferença: Parâmetros Para Reflexão Da Trajetória} Escolar Dos Alunos Imigrantes

\section{Inequality And Difference: Parameters For Reflection Of Students ' School Experience Immigrants}

Dr. Facundo Abalo

Doctor en Comunicación -Universidad Nacional de La Plata. Magister en Artes - Universidad de Buenos Aires. Profesor adjunto e investigador - UNLP/UBA. Publicó el libro "Arte y Liminalidad", además deartículos en revistas culturales, diarios nacionales y publicaciones académicas sobre la articulación entre Arte y Comunicación. Es Director de la Editorial de la Universidad de La Plata EDULP. Secretario Académico de la Carrera de Posgrado en Periodismo Cultural y Miembro del Comité Académico del Doctorado en Comunicación.

\section{Resumen}

Desde sus comienzos, la educación en Argentina tuvo una perspectiva universalista, plasmada en la Ley de Educación Común de 1884, la cual consagró la formación gratuita, laica y obligatoria. Más que un derecho, fue sancionada como una necesidad del Estado. Primero, frente a las masas criollas, y luego, ante la urgencia de argentinizar a los extranjeros provenientes de las oleadas migratorias.

Palabras chave: desigualdad, trayectos escolares, personas trans.

\begin{abstract}
Since its inception, education in Argentina was a universalist perspective, embodied in the law of common education of 1884, which enshrined free, secular and mandatory training. More than a right, was sanctioned as a necessity of the State. First, Creole masses, and then, given the urgency of argentinizar the waves of migration from foreigners.
\end{abstract}

Keywords: inequality, school trips, trans people. 


\section{Introducción}

En ese marco, y valorizada como espacio de socialización, la escuela pretendió ser un ámbito en el cual se suspendieran los conflictos del mundo adulto: fundamentalmente el tratamiento dispar y la segregación propios de una sociedad no equitativa. Sin embargo, la escuela argentina jamás fue el segundo hogar, ni tampoco se constituyó como el espacio inclusivo que ostentaba. La escuela como ámbito de disciplinamiento - fundamentalmente de los cuerpos - ha sabido cobijar solo aquello que ella misma fue creando. Paradójicamente, se ha definido y legitimado con esta ilusoria noción inclusiva y universalista. Ilusión universalista que comporta una doble cara: universal en sus contenidos y universal en sus alcances.

Este carácter universalizante ofrece claras limitaciones al momento de pensar las articulaciones entre escuela y sexualidad. La escuela reproduce el ideal de familia monogámica y heterosexual, pero en el mismo movimiento, calla los procesos violentos que ella misma ejecuta para sostener dicho ideal, e invisibilizar todo aquello que permanece por fuera. La institución escolar determina qué cuerpos reconoce como válidos y cuáles son disimulados o excluidos. Así comienza a

${ }^{1}$ Datos publicados en La gesta del nombre propio. Informe sobre la situación de la comunidad travesti en entenderse por qué el $64 \%$ de las mujeres trans que afirman haberse reconocido en dicha identidad antes de los 13 años no terminó la escuela primaria. Al mismo tiempo de aquellas que lograron terminar la primaria, menos del $10 \%$ completo los estudios secundarios ${ }^{1}$. Esta no es la misma situación de los varones trans que fueron relevados para este trabajo de investigación, donde se comprueba que, en la mayoría de los casos, se completo la educación primaria y secundaria.

Cuando se compara las trayectorias escolares del colectivo trans se advierte que, para poder completar los estudios secundarios, lo habitual es repetir y reiniciar los estudios de manera intermitente en diferentes escuelas, hecho que equivaldría una trayectoria escolar interrumpida o fragmentada. Los motivos de esa interrupción no se vinculan a la necesidad económica de ingresar al mundo laboral - como sucede en otros sectores sociales -, sino centralmente asociada a la violencia ejercida por sus propios compañeros o las autoridades del las instituciones educativas. Que gran parte de las trayectorias escolares de las personas trans estén atravesadas por situaciones de cambios de escuelas, repeticiones de año o deserciones (más ligadas a exclusiones) pone de relieve la dificultad de la institución para tolerar todo aquello que excede o no reconocido por la norma. 
Su universal es de niños y niñas, claramente diferenciados, con una sexualidad latente pero invisible, que no debería manifestarse en el ámbito escolar. Niños y niñas que nada tienen que preguntarse sobre su propia sexualidad porque la respuesta vendrá sola en el futuro: el deseo unívoco hacia el sexo opuesto.

De esta manera, y teniendo en cuenta que la mayoría de las personas trans ha sufrido algún tipo de violencia (el $91,4 \%$ de las encuestadas, según los datos proporcionados por la fuente antes mencionada), la escuela ocupa el tercer puesto en la lista de espacios donde recibieron agresiones, por debajo de la comisaría y la calle.

En la escuela, la segregación y la agresión son transmitidas especialmente por parte de compañeros o estudiantes de años superiores. Los docentes, tienden a proteger la diferencia a través del disimulo, en el mejor de los casos; intentan reducir el daño, y con ello la visibilidad, bajo su aparente protección, pero nunca es una situación conflictiva que se trabaja desde el aula.

La mayoría de las personas entrevistadas para la presente investigación no se reconocía como trans durante su trayectoria escolar. Más que una identidad de género definida, en la infancia y la adolescencia percibían que eran diferentes, siendo la escuela la que terminó nominando esa diferencia.
En la mayoría de las entrevistas y testimonios persiste el deseo de terminar los estudios o iniciar una carrera universitaria, a la vez que el temor de ser nuevamente rechazadas:

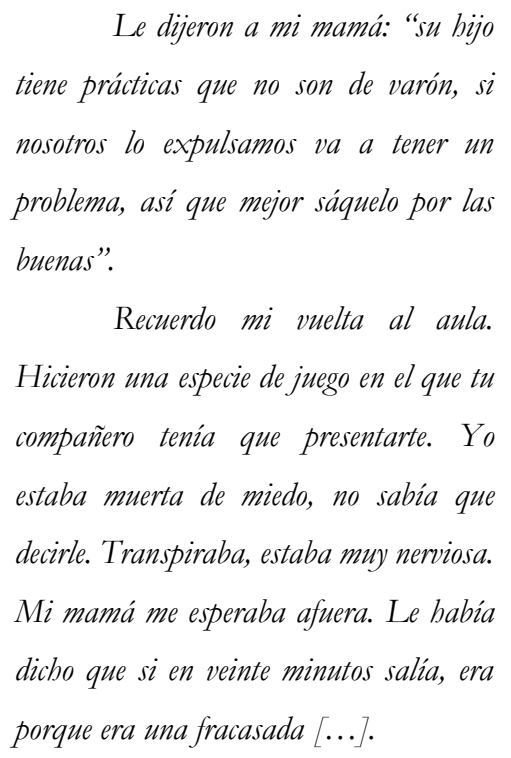

Entre las personas trans encuestadas por Berkins y Fernández, únicamente el 11\% estudia en la actualidad, aunque entre aquellas que no lo hacen, el 70\% desearía poder hacerlo. Entre las causas por las cuales no se completan los estudios, en primer lugar se encuentra el miedo a ser discriminadas.

Teniendo en cuenta estas estadísticas, este trabajo se constituye como una reflexión teórico-política que intenta hacer foco sobre los procesos de recepción, pero vinculados a las construcciones identitarias en torno al género y las interpelaciones emancipatorias. Es decir, no pretende problematizar el género y la sexualidad (cuestiones más complejas que no se intentan abordar aquî), sino para observar de manera 
indicial los modos de relacionarse con la lectura de un colectivo abyecto dentro del sistema educativo. En este sentido, el trabajo de campo no se propuso indagar sobre las problematizaciones y complejidades en relación a las construcción genérica de las/los entrevistados, sino cómo el vínculo que establecían estos sujetos con la lectura se hallaba atravesado por la institución escolar como espacio donde se administran las destrezas y capitales sobre qué y cómo leer, y su indefectible articulación con las condiciones de su exclusión.

Tal como afirman Diana Maffia y Mauro Cabral en Sexualidades migrantes. Género y transgénero: ${ }^{2}$

En los años 70, la irrupción de la categoría de género en la teoría feminista permitió el florecimiento de una serie de análisis que procuraban derrotar los estereotipos vinculados a la identidad femenina y masculina, a sus roles sociales y a sus relaciones de poder. La operación consistía principalmente en dos pasos: primero, diferenciar sexo de género, considerando al segundo una lectura cultural del sexo biológico, asignado dicotómicamente según la anatomía. Segundo, mostrar que las diferencias de género atraviesan toda la vida social, dividiéndola y organizándola simbólicamente. Desnaturalizaban así los roles femenino y masculino propios del

${ }^{2}$ Maffia, M. (comp). (2003). Sexualidades migrantes. Género y transgénero. Editorial Feminaria. género, pero sin discutir la "naturalidad" del sexo.

Muchos análisis contemporáneos conservan esta lectura en dos niveles. No se discute la realidad de las diferencias sexuales, sino la legitimidad de los estereotipos construidos por la sociedad sobre esas diferencias, como si el sexo constituyera una materialidad inapelable. Sostenemos que el sexo anatómico mismo, su propia presunta dicotomía, son producto de una lectura ideológica. Una ideología de género que antecede la lectura misma de los genitales, que no permite hablar de un sexo natural, y que es lo suficientemente fuerte como para disciplinar los cuerpos cuando no se adaptan cómodamente a la lectura que se espera bacer de ellos.

La influencia de ideas posestructuralistas, particularmente de Michel Foucault, dieron lugar a una reacción general que llamó al replanteamiento de estas cuestiones y su binarismo, como así también a la historización de sus términos y significados en el contexto de la ciencia y la tecnología. Así, diversos autores examinaron nuevamente las aspectos del cuerpo físico y la influencia del discurso en la construcción del sexo (Butler, 1990), y la dualidad cuerpo/cultura (Haraway, 1991). En su historia de la distinción sexo/género, la filósofa feminista de la ciencia, Haraway (1991) cita las siguientes fuentes de la conceptualización del género en el período de postguerra: la sexología del siglo XIX; los descubrimientos de la 
endocrinología bioquímica y psicológica desde 1920; los estudios sobre la psicobiología de la diferencia sexual; las hipótesis relacionadas al dimorfismo sexual a nivel hormonal, genético y neurológico; y las primeras operaciones de cambio de sexo (Christine Jorgensen en 1952 y Roberta Cowell en 1954).

El pensamiento de Butler (1990, 1993) emergió como una tentativa de replantearse la distinción sexo/género, o mejor dicho de colapsar sus conceptos y problematizar la categorización binaria de los humanos y la heterosexualidad como natural. Butler estuvo fuertemente influenciada por las nociones de la categoría del sexo y el sexo ficticio de Monique Wittig, así como también por las nociones de heterosexualidad como institución social y el concepto del pensamiento recto de Gayle S. Rubin. La teoría performativa de género de Butler sostiene que la reiteración de las prácticas discursivas de sexo/género performa, es decir, materializa cuerpos e identidades de acuerdo con la norma heterosexual.

Por lo tanto, según Butler, las personas transexuales y transgéneras convierten sus cuerpos en artefactos, ejemplificando así en una forma acentuada, los procesos a los que todos estamos sujetos. Cuando Butler sostiene "nosotros también nos construimos" (más allá de los significados culturales que recibamos), privilegia aquello que podemos imaginar $y$ simbolizar a partir de quienes somos según nuestra vivencia de lo genérico, poniendo entre paréntesis el género asignado o el anatómico, demandando entonces el reconocimiento del deseo, cualquiera sea la sociedad de la que participamos.

Es importante entonces repensar en las complejas articulaciones entre diferencia diversidad e identidad. A pesar de esta distinción en los enfoques entre universalistas y comunitaristas, ambos coinciden en un punto: en el de partida, constituido por la idéntica cualificación de la "diversidad" sobre la que instaura "lo político". La diversidad es considerada como un producto o resultado de la alteridad y la coexistencia de identidades culturales sustantivas definidas de manera previa.

Para estas perspectivas, las identidades culturales sustantivas compiten por el reconocimiento en el marco de la necesidad de establecer criterios igualitarios de distribución en un ámbito de diálogo neutral o en el espacio de un Estado instaurador de un régimen de tolerancia multicultural hacia la fragmentación.

Cabe señalar aquí, que los enfoques citados apenas tematizan sobre la estratificación clasista o en cuanto mucho se la considera función de otra instancia, como ser la etnicidad. El liberalismo obstruye la diferencia y desdibuja la desigualdad en su afán de establecer un plano neutral de negociación; y el multiculturalismo 
comunitarista la considera un tipo especial de "diferencia cultural" o, como ya se ha dicho, una mera función que imposibilita los distintos dispositivos de tolerancia al producir una radicalización de la diferencia cultural.

Tal como plantea Flavio Rapisardi ${ }^{3}$ :

$$
\text { (...) el debate contemporáneo }
$$
entrampa a la política de las identidades diferenciales o politica de las diferencias en una consideración meramente cultural, en tanto exige las dos cuestiones planteadas: por un lado, considera a la existencia de identidades culturales sustantivas y preconstituidas como pivotes de las regulaciones políticas; por el otro, relega y divorcia el problema de la desigualdad, enmascarándolo detrás del reclamo identitario cultural (2003: 39).

En relación a estas consideraciones, Judith Butler abre un espacio de revisión cuando se pregunta: ¿es solamente una cuestión de reconocimiento cultural cuando las sexualidades y las identidades no-normativas son marginadas y descalificadas, y cuando éstas reclaman derechos? Este cuestionamiento, y los debates que implica, delinean una postura crítica, en tanto se busca desconstruir la visión reductiva de lo cultural que se apunta contra la denominada política de la diferencia, y en tanto se propone recuperar la dimensión material presente articulada por toda identidad. En este sentido, Rapisardi expresa que

${ }^{3}$ Rapisardi, F. (2003). Identidad, diferencia $y$ desigualdad. Una crítica al debate contemporáneo. En Sexualidades migrantes. Género y transgénero.

\begin{abstract}
Una perspectiva crítica exige, entonces, desmantelar lo que las tradiciones politicas liberales o comunitaristas adoptan como punto de partida, las cuales confinan la política de la diferencia a una reductiva versión de culturalismo: proponer identidades sustantivas y preexistentes, distribuidas en un mapa social, que se autodeterminan como pivotes de un régimen regulativo que las considera como partes constitutivas de un plano de inmanencia inalterable sobre el que debe operar. (2003: 40)
\end{abstract}

Contra esta posición, si abordamos al régimen de la diferencia que rige al mapa social - no como una derivación-reflejo de identidades preconstituidas, sino como articulación específica de modos jerarquizantes de reparto- $y$ a las identidades como configuraciones producidas a partir de los antagonismos articulados por el régimen operante, se podrán corroer los intentos de encorsetar las políticas de la diferencia en el acotado campo de las propuestas identitarias de la política del debate contemporáneo. Esta operación teórica no consiste en la simple inversión de las propuestas de las denominadas políticas de la identidad, sino que se funda en la crítica a la misma noción de identidad como lugar sustantivo de autentificación. Es decir, las configuraciones, en tanto articulaciones de operaciones antagónicas $\mathrm{y}$ de poder, nunca remiten a comunidades 
homogéneas, sino a intereses políticos en discordia y en tensión que se pronuncian culturalmente en experiencias culturales comunes de desigualdad.

En este sentido, la cultura puede ser historizada como una superficie en la que se inscriben y articulan las condiciones materiales de la experiencia como campos de conflictos hegemónicos, atravesados por la exclusión. Desde esta posición, se tematizan las configuraciones como fenómenos históricos, es decir, modalidades articuladas culturalmente en la materialidad de lo social en función de distribuciones materiales y simbólicas inequitativas.

\section{Consideraciones Finales}

En las instituciones escolares se desarrolla a partir de una regulación de la sexualidad que se vincula con el modo de producción, en tanto exige la heterosexualidad obligatoria y la familia como requerimientos sistemáticos de las formas sociales aptas para la reproducción de las relaciones sociales hegemónicas. Por esto, la etnia, orientación sexual, género y cuestiones etarias se pueden constituir en un modo de la lucha de clases, entendida esta no como contradicción estructural, sino como enfrentamientos a los modos de dominio, autoridad, control, propiedad y reparto. Asimismo, la proliferación y no la mera diferenciación multicultural llevan, como sostiene Fabricio Forastelli (2006), a "revisar los sistemas y organizaciones de la autoridad en el terreno político y cultural”, en tanto articulan y hacen interactuar "registros culturales" (sentimientos, sentidos, etc.) y "registros políticos" que exigen el reordenamiento de lo social y de las instituciones.

Configuración e identificación y no identidad pre-constituida son la claves de esta cita. En esta propuesta, la identidad no preexiste ni se estabiliza en atributos, sino que es una configuración articuladora a partir de distintos antagonismos. La identidad de género travesti es concebida como una articulación y proceso en el que se cuestionan los modos de dominio y la reproducción del sistema político de relaciones hegemónicas, es decir, civiles, culturales y económicas. En esta perspectiva, la identidad de género travesti aparece como un constructo que relaciona y pone en juego dispositivos de exclusión y alianzas en función de la tensión y el antagonismo: "ser travesti es ubicarse en un punto de antagonismo en el que renegocia de manera constante sus identificaciones y alianzas en función de la crítica a la subalternidad" (Berkins, 2005).

\section{Bibliografía}

BERKINS, L. y Fernández, J. La gesta de nombre propio. Informe sobre la situación de la comunidad travesti en la Argentina. Buenos Aires: Ediciones Madres de Plaza de Mayo, 2005. 
BOURDIEU, P. (2007). El sentido práctico. Buenos Aires: Siglo XXI Editores.

. Capital cultural, escuela y espacio social.

Buenos Aires: Siglo XXI Editores, 2008.

. La distinción. Criterios y bases sociales del gusto. Barcelona: Taurus

BUTLER, J. (2004). Lenguaje, poder e identidad. Madrid: Síntesis, 2012.

Deshacer el género. Barcelona: Paidós, 2006.

FOUCAULT, M. (1969). ¿Qué es un autor? Colección Textos Minimos. México: Universidad Autónoma de Tlaxcala. 1985.

. El orden del discurso. México: Facultad de Filosofía y Letras UNAM. Ediciones Populares, 1982.

, Los anormales. México: Fondo de

Cultura Económica, 2007.

GOFFMAN, E. Estigma: la identidad deteriorada. Buenos Aires: Amorrortu, 1998.

KENNARD, J. Ourself behind ourself: A Theory for Lesbian Readers. Baltimore: The John's Hopkins University Press, 1984.

KOESTENBAUM, W. Wilde's Hard Labour and the Birth of Gay Reading. Baltimore: The John's Hopkins University Press, 1990.
MAHMOOD, S. Teoría feminista y el agente social dócil: algunas reflexiones sobre el renacimiento islámico en Egipto, en Liliana Suárez y Rosalva Aída Fernández (eds.), Descolonizando el feminismo. Teorías y prácticas desde los márgenes. Madrid: Cátedra, pp. 165-222, 2008.

RAPISARDI, F. Identidad, diferencia y desigualdad. Una critica al debate contemporáneo. En Sexualidades migrantes. Género y transgénero, 2003.

Raras teorias del sur. Una experiencia de diversidades y desigualdad politico sexual. En Orientaciones No9. Pp 53-75. 2005.

SEGATO, R. Las estructuras elementales de la violencia. Buenos Aires: Prometeo, 2013.

SPIVAK, G. ¿Puede el subalterno hablar? Buenos Aires: El cuenco de plata, 2011. 